\title{
In-Source Decay and Fragmentation Characteristics of Peptides Using 5-Aminosalicylic Acid as a Matrix in Matrix-Assisted Laser Desorption/Ionization Mass Spectrometry
}

\author{
Motoshi Sakakura and Mitsuo Takayama \\ Graduate School of Nanobiosciences, Yokohama City University, Yokohama, Japan
}

\begin{abstract}
The use of 5-aminosalicylic acid (5-ASA) as a new matrix for in-source decay (ISD) of peptides including mono- and di-phosphorylated peptides in matrix-assisted laser desorption/ionization (MALDI) mass spectrometry (MS) is described. The use of 5-ASA in MALDI-ISD has been evaluated from several standpoints: hydrogen-donating ability, the outstanding sharpness of molecular and fragment ion peaks, and the presence of interference peaks such as metastable peaks and multiply charged ions. The hydrogen-donating ability of several matrices such as $\alpha$-cyano-4hydroxycinnamic acid (CHCA), 2,5-dihydroxybenzoic acid (2,5-DHB), 1,5-diaminonaphthalene $(1,5-\mathrm{DAN})$, sinapinic acid (SA), and 5-ASA was evaluated by using the peak abundance of a reduction product $[\mathrm{M}+2 \mathrm{H}+\mathrm{H}]^{+}$to that of non-reduced protonated molecule $[\mathrm{M}+\mathrm{H}]^{+}$of the cyclic peptide vasopressin which contains a disulfide bond (S-S). The order of hydrogendonating ability was 1,5-DAN $>$ 5-ASA $>2,5-\mathrm{DHB}>\mathrm{SA}=\mathrm{CHCA}$. The chemicals 1,5-DAN and 5-ASA in particular can be classified as reductive matrices. 5-ASA gave peaks with higher sharpness for protonated molecules and fragment ions than other matrices and did not give any interference peaks such as multiply-protonated ions and metastable ions in the ISD mass spectra of the peptides used. Particularly, 1,5-DAN and 5-ASA gave very little metastable peaks. This indicates that 1,5-DAN and 5-ASA are more "cool" than other matrices. The 1,5-DAN and 5-ASA can therefore be termed "reductive cool" matrix. Further, it was confirmed that ISD phenomena such as $\mathrm{N}-\mathrm{C} \alpha$ bond cleavage and reduction of $\mathrm{S}-\mathrm{S}$ bond is a single event in the ion source. The characteristic fragmentations, which form $a$ - and $(a+$ 2)-series ions, $[\mathrm{M}+\mathrm{H}-15]^{+},[\mathrm{M}+\mathrm{H}-28]^{+}$, and $[\mathrm{M}+\mathrm{H}-44]^{+}$ions in the MALDI-ISD are described. (J Am Soc Mass Spectrom 2010, 21, 979-988) (c) 2010 American Society for Mass Spectrometry
\end{abstract}

$\mathrm{T}$ The role of mass spectrometry (MS) in protein sciences such as proteomics has become increasingly important due to its outstanding sensitivity and rapidity. It is of importance to recognize that the analysis of proteins using MS generally pertains to the analysis of peptides obtained upon enzymatic digestion of proteins. MS coupled to soft ionization methods such as matrix-assisted laser desorption/ionization (MALDI) [1-3] and electrospray ionization (ESI) [4, 5] have been used to obtain qualitative information for peptide-mass fingerprinting (PMF), amino acid sequencing and analysis of post-translational modifications (PTMs), and quantitative information about protein(s) expressed from a genome [6, 7]. The most valuable information for protein identification including PTMs is the amino acid

Address reprint requests to Professor M. Takayama, Graduate School of Nanobioscience, Yokohama City University, Yokohama, 236-0027 Japan. E-mail: takayama@yokohama-cu.ac.jp sequences that are available from tandem mass spectrometry and other MS degradation methods.

Of the mass spectrometric dissociation methods used for identifying proteins, electron capture dissociation (ECD) [8] and electron-transfer dissociation (ETD) [9] coupled to ESI and in-source decay (ISD) coupled to MALDI [10] have been noted from the standpoint of specific cleavage at the $\mathrm{N}-\mathrm{C} \alpha$ bond on the peptide backbone because conventional methods such as collision-induced dissociation (CID) leads to nonspecific cleavage of the peptide backbone and the loss of PTM functional groups [11]. The nonspecific cleavage gives backbone cleaved fragments such as $a-, b-, x-$, and $y$-series ions (Scheme 1 upper [12] and the loss of $\mathrm{NH}_{3}$ and/or $\mathrm{H}_{2} \mathrm{O}$ from those fragments, and furthermore, the nonspecific cleavage complicates the analysis of resulting spectra. In contrast, both ESI-ECD/ETD and MALDI-ISD methods use hydrogen transfer to the carbonyl oxygen on the peptide backbone with subsequent radical-induced cleavage at the $\mathrm{N}-\mathrm{C} \alpha$ bond in 


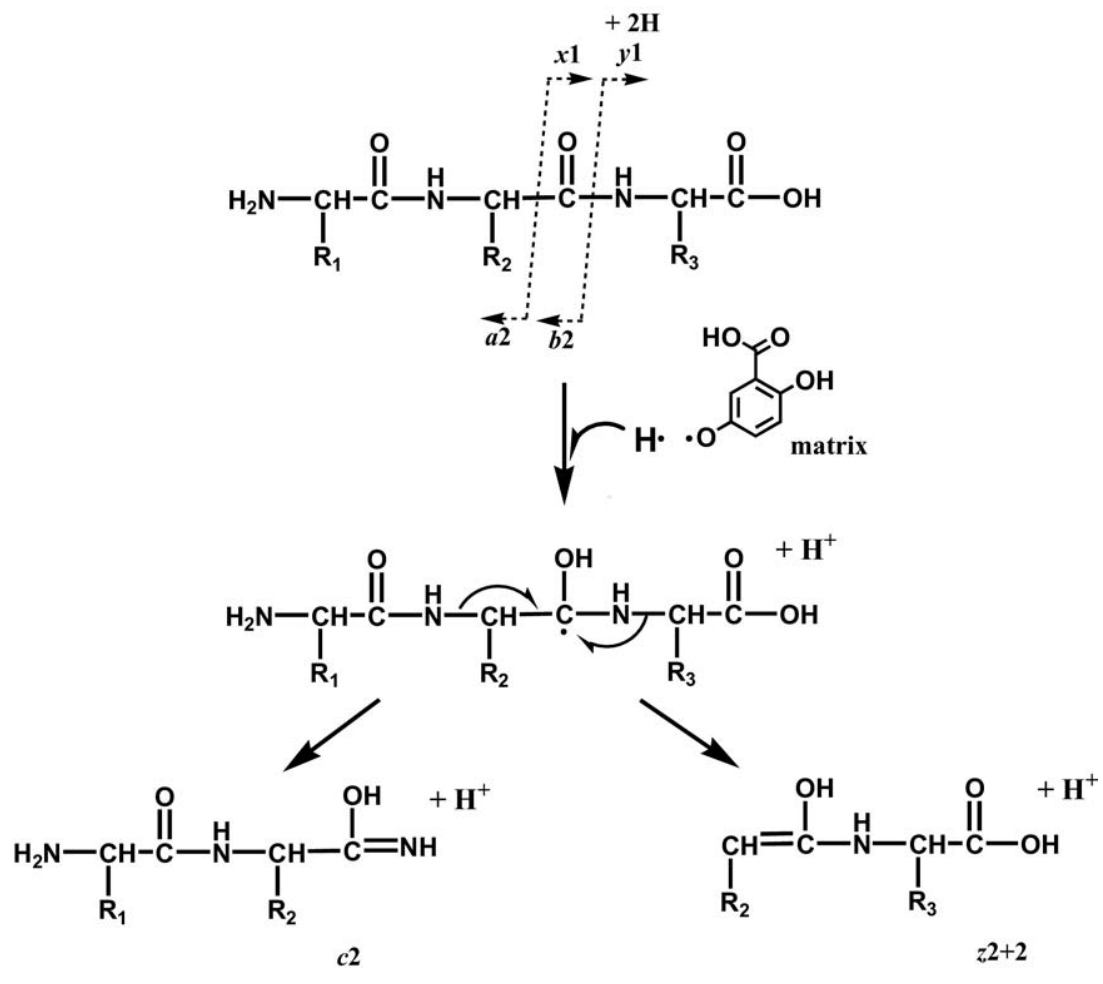

Scheme 1

principle $[13,14]$. As a result, both methods give $c$ - and $z$ - or $(z+2)$-series ions (Scheme 1 lower) [13] without the loss or degradation of PTM functional groups. The resulting spectra are very simple and the analysis of the sequences and PTM sites is straightforward. Therefore, the use of ESI-ECD/ETD and MALDI-ISD have been utilized as tools in the top-down approach for proteomics [11, 15].

It is interesting that for ESI-ECD/ETD and MALDIISD the hydrogen atoms play an important role in the specific cleavage at the $\mathrm{N}-\mathrm{C} \alpha$ bond. In the case of ESI-ECD/ETD, the hydrogen atoms are generated through the protons of multiply-protonated proteins $[\mathrm{M}+n \mathrm{H}]^{n+}$ being neutralized via an electron capture reaction. This means that in ECD/ETD the N-C $\alpha$ bond cleavage occurs by an intra-molecular hydrogen transfer. In contrast, the hydrogen atoms in MALDI-ISD are produced from the active hydrogens $\left(-\mathrm{OH}\right.$ and $\left.-\mathrm{NH}_{2}\right)$ of matrix chemicals such as 2,5-dihydroxybenzoic acid (2,5-DHB) [16] and 1,5-diaminonaphtalene (1,5-DAN) [17] activated by the irradiation of laser photons. It is of importance to recognize that hydrogen-donating ability is a prominent factor for the function of matrix in the MALDI-ISD. The hydrogen-donating ability can be measured by studying the ability to cleave disulfide bonds by reduction [17] or by using hydrogen scavengers as recently reported by Demeure et al. [18]. They reported a method for selecting the optimum MALDIISD matrix suitable for top-down proteomics and that the order of hydrogen-donating ability was picolinic acid $(\mathrm{PA})>1,5-\mathrm{DAN}>2,5-\mathrm{DHB}>$ sinapinic acid (SA) $>\alpha$-cyano-4-hydroxycinnamic acid (CHCA). Of these matrices, those that are practically effective for the MALDI-ISD of peptides and proteins are 2,5-DHB and 1,5 -DAN. These chemicals are reductive in nature. The chemicals suitable for the MALDI-ISD of peptides have to satisfy the following requirements:

1. Hydrogen-donating ability to allow the formation of the radical species of peptides and/or proteins (Scheme 1).

2. Efficient desorption and ionization of peptides to form protonated molecules $[\mathrm{M}+\mathrm{H}]^{+}$.

Although the above requirements are satisfied by both 2,5-DHB and 1,5-DAN, other matrix chemicals for MALDI-ISD should be sought to allow further improvements to be made and to address current shortcomings, e.g., the appearance of interference peaks originating from metastable decay and multiply-protonated molecules when using 2,5-DHB and the appearance of cluster ion peaks with 1,5-DAN together with its sublimation properties and the background observed with its use. Furthermore, the chemical 1,5-DAN is a type of amino-naphthalene, which has carcinogenic activity [19]. It is not recommended therefore to usually use $1,5-\mathrm{DAN}$ as a matrix in MALDI-ISD from the standpoint of its safety in human beings. With regard to a search strategy for new matrices for MALDI-ISD, it is important to recognize that the site of active hydro- 
gens releasing hydrogen atoms from the matrices may be the 5-hydroxy group in 2,5-DHB [16] and 1and 5-amino groups in 1,5-DAN [17]. Here we report 5-aminosalicylic acid (5-ASA) as a novel matrix suitable for the MALDI-ISD of peptides including phosphorylated peptides.

\section{Experimental}

\section{Materials}

Adrenocorticotropic hormone fragment 18-35 (ACTH1835, Mr 1979.1): RPVKVYPNGAEDESAEAF, monophosphorylated peptide [pTyr ${ }^{6}$ ]-ACTH18-35 (Mr 2059.1): RPVKVY $\left(\mathrm{PO}_{3} \mathrm{H}_{2}\right)$ PNGAEDESAEAF, di-phosphorylated peptide $\left[\mathrm{pTyr}^{6}, \mathrm{pSer}^{14}\right]$-ACTH18-35 (Mr 2139.1): RPVKVY $\left(\mathrm{PO}_{3} \mathrm{H}_{2}\right)$ PNGAEDES $\left(\mathrm{PO}_{3} \mathrm{H}_{2}\right) \mathrm{AEAF}$, [Arg $\left.{ }^{36}\right]-$ ACTH18-36 (Mr 2135.3); RPVKVYPNGAEDESAEAFR, ACTH19-36 (Mr 1920.0): PVKVYPNGAEDESAEAFP, [Arg ${ }^{36}$ ]-ACTH19-36 (Mr 1979.1): PVKVYPNGAEDESAEAFR, [ $\mathrm{Arg}^{22}$ ]-ACTH22-39 (Mr 2042.1): RYPNGAEDESAEAFPLEF, deuterium-labeled dodecapeptide (Mr 1433.6): RLGNQWA $\left(\mathrm{d}_{3}\right)$ VG $\left(\mathrm{d}_{2}\right)$ DLAE, and [ $\mathrm{Arg}^{8}$ ]-vasopressin (Mr 1084.2): CYFQNCPRG-NH $\mathrm{NH}_{2}$ were purchased from peptide institute (Minoh, Osaka, Japan). The MALDI matrices $\alpha$-cyano-4-hydroxycinnamic acid (CHCA), 2,5dihydroxybenzoic acid (2,5-DHB), 5-aminosalicylic acid (5-ASA), 1,5-diaminonaphtalene (1,5-DAN) and sinapinic acid (SA) were purchased from SIGMA ALDRICH (Steinheim, Germany). Trifluoroacetic acid (TFA) and acetonitrile were purchased from Wako Pure Chemical (Osaka, Japan). Water used in all experiments was purified using a MilliQ water purification system of Millipore (Billerica, MA, USA). All reagents were used without further purification.

\section{MALDI-TOF MS}

MALDI-TOF mass spectra were acquired on an AXIMA-CFR instrument (Shimadzu Corp., Kyoto, Japan) with positive ion reflectron mode. A nitrogen laser (337 nm wavelength, 4 ns pulse length; Spectra-Physics, Meguro, Tokyo, Japan) was used to irradiate the sample for desorption and ionization. The laser beam was focused to a spot of 100 to $200 \mu \mathrm{m}$ in diameter on the target. The ISD mass spectra were obtained with higher laser fluence than the threshold fluence for $[\mathrm{M}+\mathrm{H}]^{+}$ ion detection, although the appropriate fluence for ISD fragment formation strongly depend upon matrix used. Assuming the spot diameter 100 or $200 \mu \mathrm{m}$, the appropriate laser fluences $\left(\mathrm{J} / \mathrm{m}^{2}\right)$ for the ISD (and the threshold) were about 764 (484) or 191 (121) for 1,5-DAN, 1210 (892) or 303 (223) for 2,5-DHB, and 6497 (3567) or 1624 (892) for 5-ASA. The acceleration potential was set to 20 $\mathrm{kV}$ using a gridless-type electrode. The delayed time for ion extraction was 238 ns. The analyte peptide was dissolved in water at a concentration of $10 \mathrm{pmol} / \mu \mathrm{L}$. Then $5 \mu \mathrm{L}$ of analyte solution was mixed with $5 \mu \mathrm{L}$ of saturated matrix of $0.1 \%$ TFA in water/acetonitrile (1:1 vol/vol). A $1 \mu \mathrm{L}$ of sample solution was deposited onto a MALDI sample plate and the solvents were removed by drying in air at room-temperature. Mass spectra were acquired by accumulating 100 laser shots.

\section{Results and Discussion}

ISD Spectra of Peptides with 5-ASA, 2,5-DHB, and 1,5-DAN

Figure 1 shows the comparison of positive-ion MALDIISD spectra of ACTH18-35 obtained with three different

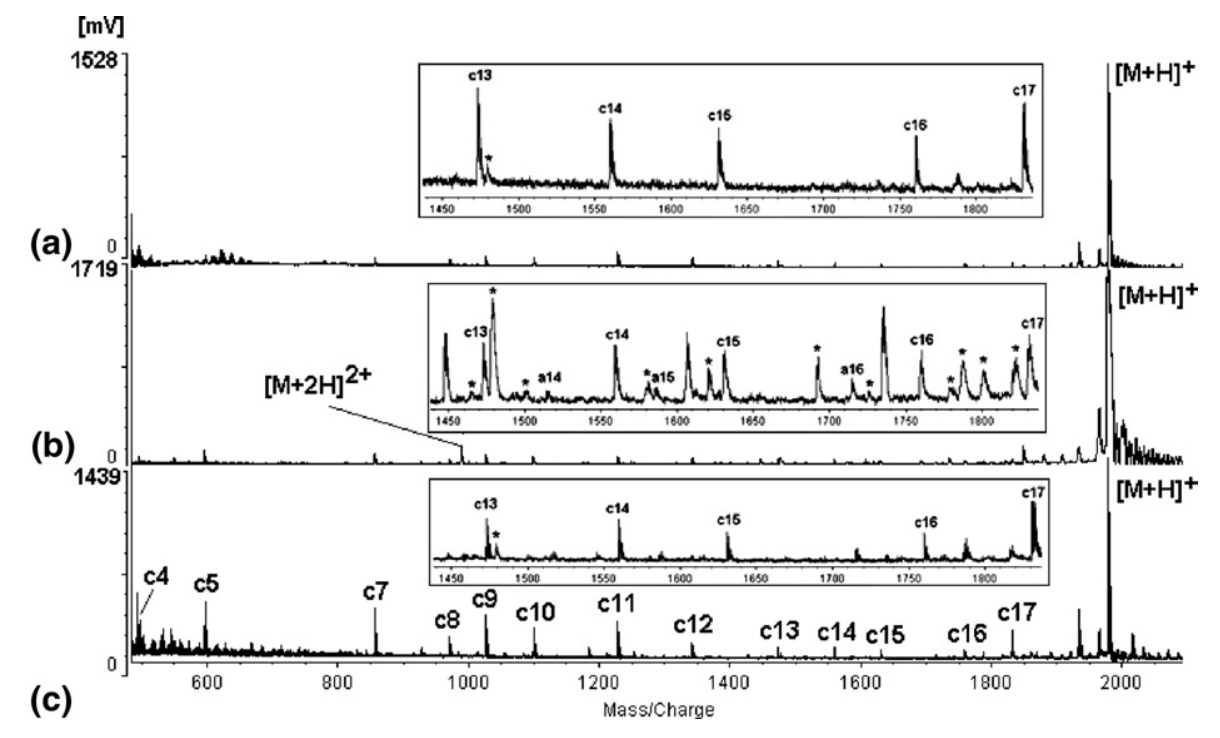

Figure 1. Positive-ion MALDI-ISD spectra of ACTH18-35 (Mr 1979.1) obtained with (a) 1,5-DAN, (b) 2,5-DHB, and (c) 5-ASA. The insets represent the partial mass spectra in the range of $\mathrm{m} / \mathrm{z}$ 1450-1850. Asterisk indicates metastable peaks. 
matrices 5-ASA, 2,5-DHB, and 1,5-DAN. The ordinate of the mass spectra was represented by the voltage corresponding to ion abundance. The voltages of protonated molecules $[\mathrm{M}+\mathrm{H}]^{+}$as the base peak obtained with the appropriate laser fluences for 5-ASA (51.0 $\mu \mathrm{J} /$ pulse), 2,5-DHB (9.5 $\mu \mathrm{J} /$ pulse), and 1,5-DAN (6.0 $\mu \mathrm{J} /$ pulse) were 1439,1719 , and $1528 \mathrm{mV}$, respectively. All the spectra show $c$-series ions originating from cleavage at the $\mathrm{N}-\mathrm{C} \alpha$ bond on the peptide backbone. The use of 5-ASA and 2,5-DHB produced ions (monoisotopic mass) from c3 $(\mathrm{m} / \mathrm{z} 370)$ to $\mathrm{c} 17(\mathrm{~m} / \mathrm{z} 1830)$ with the exception of the c6 ion corresponding to cleavage at Tyr5-Pro6, while the $\mathrm{c} 3$ and $c 4(\mathrm{~m} / \mathrm{z} 498)$ ions are not observed in 1,5-DAN due to interference from the matrix ions such as at $m / z 158\left(\mathrm{M}^{+}\right), m / z 314(2 \mathrm{M}-$ $2 \mathrm{H})^{+}, m / z 467(3 \mathrm{M}-7 \mathrm{H})^{+}$and $m / z 624(4 \mathrm{M}-8 \mathrm{H})^{+}$. (Figure 1a). The production of excessively high matrix cluster background ions in 1,5-DAN has been pointed out by Soltwisch et al. [20]. The use of 5-ASA and 1,5-DAN did not produce any multiply-protonated molecules such as $[\mathrm{M}+2 \mathrm{H}]^{2+}$ at $m / z$ 989, whereas 2,5-DHB gave an abundant peak corresponding to the doubly-protonated molecule (Figure 1b). Furthermore, the use of 5-ASA and 1,5-DAN resulted in a much lower level of metastable peaks than was observed in the ISD spectrum with 2,5-DHB (the inset of Figure 1b). The outstanding characteristics of the ISD spectrum obtained with 5-ASA compared with other matrices were the high quality separation of isotope peaks of the molecular and fragment ions, as shown in Figure 2. The peak broadening and the high degree metastable decay originate from the kinetic energy dispersion and the contents of internal energy in the molecules vibrationally excited, respectively. The internal energy content can often be explained from the standpoint of the criterion of "hot" or "cool" [21, 22]. Fewer metastable peaks with the use of 5-ASA indicate that the chemical 5-ASA can be classified as a more "cool" matrix, as well as 1,5-DAN than 2,5-DHB. The sharpness in the isotope peaks of the resulting molecular and fragment ions in the ISD spectra of peptides with 5-ASA was maintained even at higher laser fluences which are suitable for the appearance of ISD ion peaks over the threshold fluence for $[\mathrm{M}+\mathrm{H}]^{+}$ion detection.

The use of 5-ASA resulted in improved ISD spectra of phosphorylated peptides than those observed with 2,5-DHB and 1,5-DAN. The comparisons of positive-ion ISD spectra of mono-phosphorylated peptide [pTyr ${ }^{6}$ ACTH18-35 and di-phosphorylated peptide [pTyr ${ }^{6}$, pSer ${ }^{14}$ ]-ACTH18-35 obtained with three matrices are shown in Figures 3 and 4, respectively. The ISD spectra of these peptides obtained with 5-ASA showed $c$-series ions from $\mathrm{c} 3$ to $\mathrm{c} 17$ except for the $\mathrm{c} 6$ ion corresponding to the pTyr6-Pro7 bond cleavage. In contrast, several $c$-ions in the ISD spectra with 2,5-DHB and 1,5-DAN were interfered with by peak broadening, matrix clusters and/or metastable peaks. The peak sharpness was observed in the $[\mathrm{M}+\mathrm{H}]^{+}$ions of the ISD spectra of mono-phosphorylated peptide with 5-ASA (right hand side in Figure 3). The ISD spectrum of $\left[\mathrm{pTyr}^{6}, \mathrm{pSer}^{14}\right]-$ ACTH18-35 with 1,5-DAN did not show any useful fragment ions (Figure 4a). It is noteworthy that the loss or degradation of phosphoric group(s) in the phosphorylated peptides did not occur in the MALDI-ISD processes, although the ISD spectra with 5-ASA slightly showed the peaks of $[\mathrm{M}+\mathrm{H}-80]^{+}$corresponding the $\left[\mathrm{M}+\mathrm{H}-\mathrm{PO}_{3} \mathrm{H}\right]^{+}$(Figure $3 \mathrm{c}$ and Figure $4 \mathrm{c}$ ). The $c^{-}$, $(z+2)-$, and $y$-series ions observed in the MALDI-ISD spectra of all the peptides with 5-ASA are summarized in Table 1. The observation of $c$-series ions at low mass regions was often difficult due to the interference from peaks of matrix cluster ions.

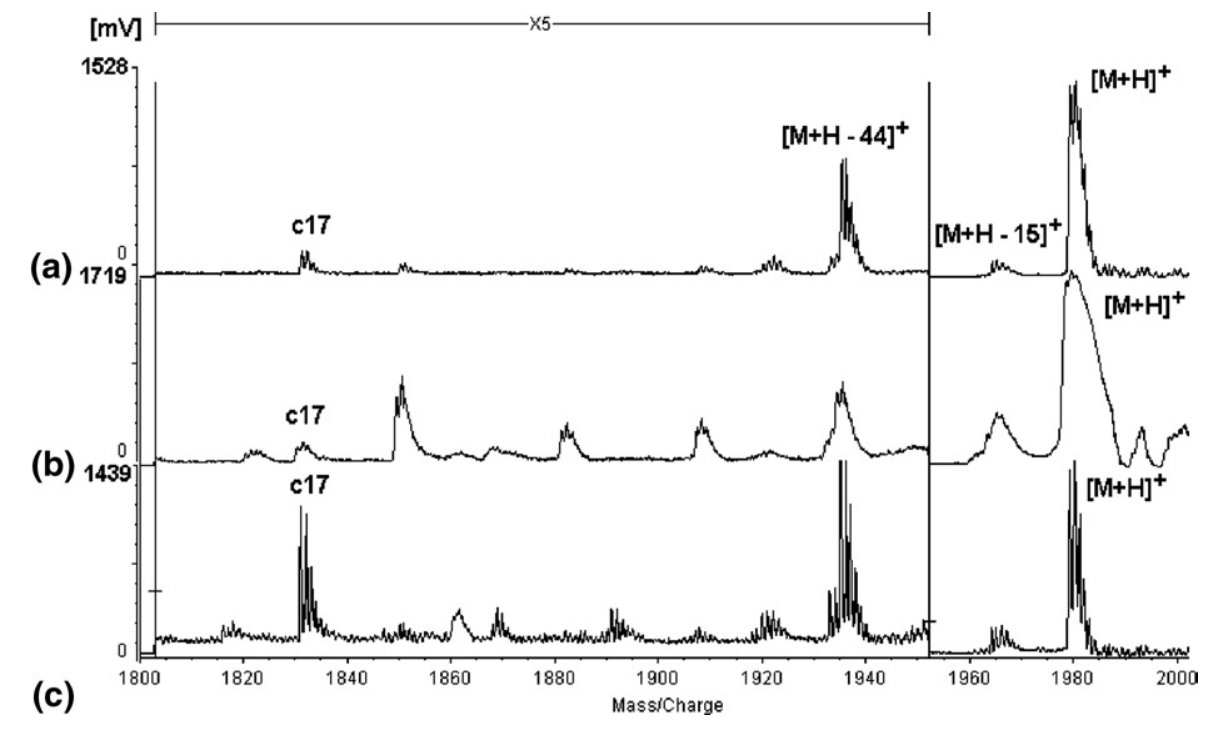

Figure 2. Partial MALDI-ISD spectra of ACTH18-35 (Mr 1979.1) obtained with (a) 1,5-DAN, (b) 2,5-DHB, and (c) 5-ASA. 


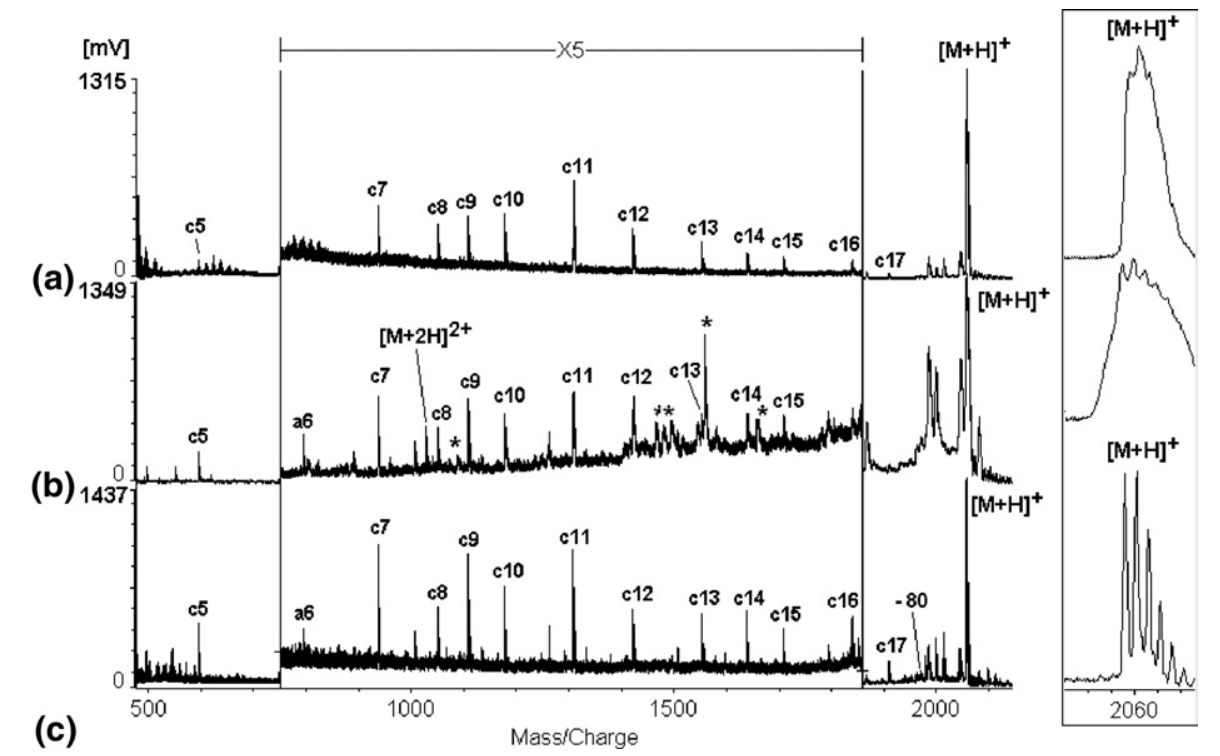

Figure 3. Positive-ion MALDI-ISD spectra of mono-phosphorylated peptide [pTyr $\left.{ }^{6}\right]-A C T H 18-35$ (Mr 2059.1) obtained with (a) 1,5-DAN, (b) 2,5-DHB, and (c) 5-ASA. Asterisk indicates metastable peaks. The right hand inset represents the peaks of protonated molecule $[\mathrm{M}+\mathrm{H}]^{+}$.

\section{Fragmentation Characteristics of MALDI-ISD Except for the $\mathrm{N}-\mathrm{C} \alpha$ Bond Cleavage}

Appropriate fragment ions in mass spectra are generally very useful for elucidation of the structure of analytes. The MALDI-ISD spectra of peptides also show informative fragments such as $a-, b-$, and $y$-series ions, as well as $c$ - and $(z+2)$-series ions originating from $\mathrm{N}-\mathrm{C} \alpha$ bond cleavage [23], although resulting ISD spectra often show broadened peaks even when a delayed extraction device and reflectron TOF are used [24]. Using 5-ASA, the fragment ions could be clearly assigned due to the sharpness of the peaks and decreased interference peaks in the MALDI-ISD spectra.

The fragment ions $[\mathrm{M}+\mathrm{H}-15]^{+}$and $[\mathrm{M}+\mathrm{H}-$ $44]^{+}$were clearly observed in the ISD spectra of peptides as shown in Figure 2. These fragments might have originated from the loss of a neutral $\mathrm{NH}$ from the $\mathrm{N}$-terminal amino group and the loss of a neutral $\mathrm{CO}_{2}$ from the C-terminal carboxyl group, respectively. The

(a)

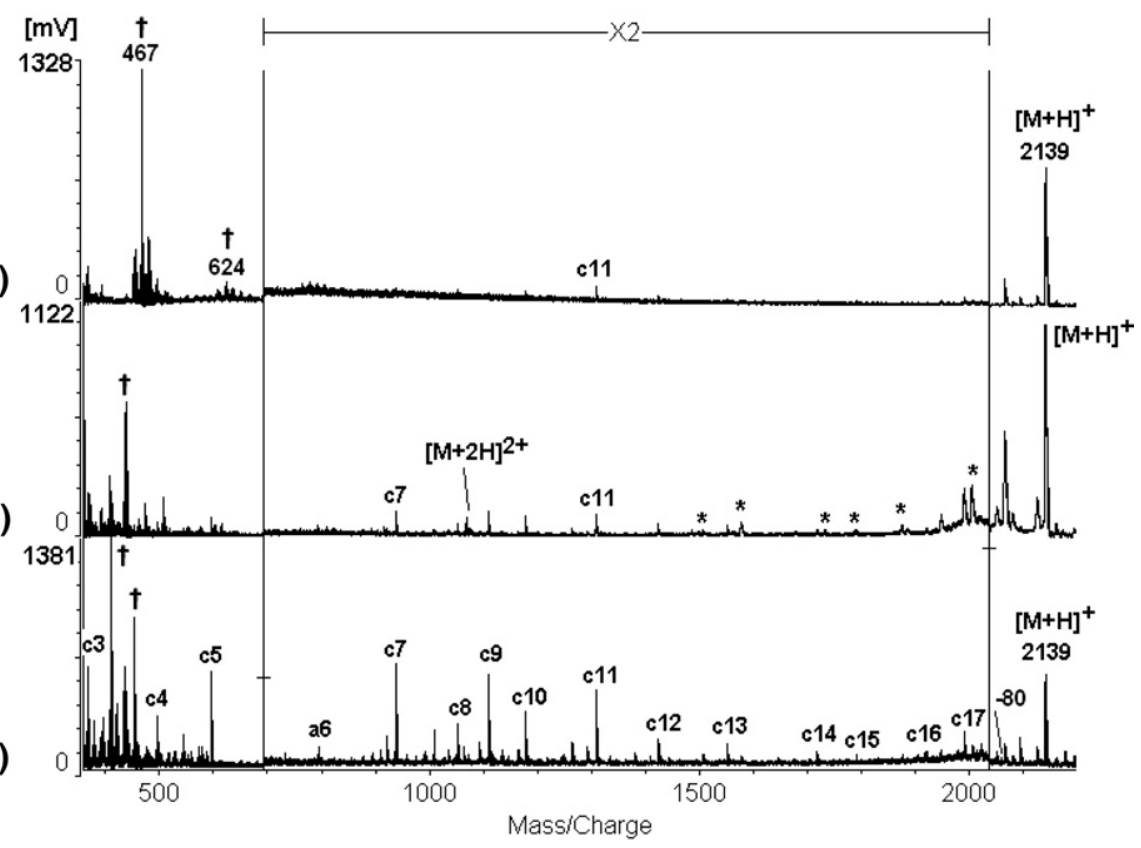

Figure 4. Positive-ion MALDI-ISD spectra of di-phosphorylated peptide $\left[\mathrm{pTyr}^{6}{ }^{6}, \mathrm{pSer}^{14}\right]$-ACTH18-35 (Mr 2139.1) obtained with (a) 1,5-DAN, (b) 2,5-DHB, and (c) 5-ASA. Asterisk and dagger indicate metastable peaks and matrix peaks, respectively. 
Table 1. Observed $c^{-},(z+2)-$, and $y$-series ions in the MALDI-ISD spectra obtained with 5-ASA matrix. The assigned positional numbers represent the cleavage sites

\begin{tabular}{|c|c|c|c|c|c|c|c|c|c|c|c|c|c|c|c|c|c|c|c|c|}
\hline Peptide & & & & & & & & erv & $c^{-}$, & + & - , an & $y$-se & ies i & & & & & & & \\
\hline & $c$ & & & 3 & 4 & 5 & & 7 & 8 & 9 & 10 & 11 & 12 & 13 & 14 & 15 & 16 & 17 & & \\
\hline \multirow[t]{2}{*}{ ACTH18-35: } & & $\mathrm{R}$ & $P$ & V & $\mathrm{K}$ & V & $\mathrm{Y}$ & $\mathrm{P}$ & $\mathrm{N}$ & G & A & $E$ & $\mathrm{D}$ & $E$ & $\mathrm{~S}$ & $A$ & $E$ & $A$ & $\mathrm{~F}$ & \\
\hline & $c$ & & & & 4 & 5 & & 7 & 8 & 9 & 10 & 11 & 12 & 13 & 14 & 15 & 16 & 17 & & \\
\hline \multirow[t]{2}{*}{ [pTyr $\left.{ }^{6}\right]-A C T H 18-35:$} & & $\mathrm{R}$ & $P$ & V & $\mathrm{K}$ & V & $\mathrm{pY}$ & $P$ & $\mathrm{~N}$ & $\mathrm{G}$ & $A$ & $E$ & $\mathrm{D}$ & $E$ & $\mathrm{~S}$ & $A$ & $E$ & A & $F$ & \\
\hline & $c$ & & & & 4 & 5 & & 7 & 8 & 9 & 10 & 11 & 12 & 13 & 14 & 15 & 16 & 14 & & \\
\hline$\left[p T y r^{6}\right.$, pSer $\left.^{14}\right]-$ & & $\mathrm{R}$ & $P$ & V & $\mathrm{K}$ & V & $\mathrm{pY}$ & $P$ & $\mathrm{~N}$ & G & $A$ & $\mathrm{E}$ & $\mathrm{D}$ & $E$ & pS & $A$ & $E$ & A & $\mathrm{F}$ & \\
\hline ACTH18-35: & $c$ & & & & & 5 & & 7 & 8 & 9 & 10 & 11 & 12 & 13 & 14 & 15 & 16 & 17 & 18 & \\
\hline \multirow{2}{*}[\mathrm{Arg}^{36}]{- ACTH18-36: } & & $\mathrm{R}$ & $P$ & V & K & V & Y & $P$ & $\mathrm{~N}$ & G & $A$ & $\mathrm{E}$ & $\mathrm{D}$ & $E$ & $S$ & $A$ & $E$ & $A$ & $\mathrm{~F}$ & \\
\hline & $c$ & & & & & & & & 8 & 9 & 10 & 11 & 12 & 13 & 14 & 15 & 16 & & & \\
\hline \multirow[t]{2}{*}{ АCTH19-36: } & & $P$ & V & K & V & $\mathrm{Y}$ & $P$ & $\mathrm{~N}$ & $\mathrm{G}$ & $A$ & $E$ & $\mathrm{D}$ & $E$ & $\mathrm{~S}$ & $A$ & $\mathrm{E}$ & $A$ & $\mathrm{~F}$ & $P$ & \\
\hline & $c$ & & & & & & & & & & 10 & 11 & 12 & 13 & 14 & 15 & 16 & & & \\
\hline \multirow[t]{4}{*}[\mathrm{Arg}^{36}]{- ACTH19-36: } & & $P$ & V & K & V & $\mathrm{Y}$ & $P$ & $\mathrm{~N}$ & G & A & $\mathrm{E}$ & $\mathrm{D}$ & $E$ & $\mathrm{~S}$ & $A$ & $E$ & $A$ & $\mathrm{~F}$ & $\mathrm{R}$ & \\
\hline & $z+2$ & & & & 15 & 14 & & 12 & 11 & 10 & 9 & 8 & 7 & & & & & & & \\
\hline & $y$ & & & & 15 & 14 & 13 & 12 & 11 & 10 & 9 & 8 & 7 & & & & & & & \\
\hline & $c$ & & & & & 5 & 6 & 7 & 8 & 9 & 10 & 11 & 12 & 13 & & 15 & 16 & 17 & & \\
\hline$\left[\mathrm{Arg}^{22}\right]-$ АCTH22-39: & & $\mathrm{R}$ & Y & $P$ & $\mathrm{~N}$ & G & A & $E$ & $\mathrm{D}$ & $E$ & $S$ & $A$ & $E$ & $A$ & $\mathrm{~F}$ & $\mathrm{P}$ & $\mathrm{L}$ & $E$ & $F$ & \\
\hline
\end{tabular}

possibility of the loss of $\mathrm{NH}$ from the N-terminal amino group is supported by the fact that the fragment ion $[\mathrm{M}+\mathrm{H}-15]^{+}$was not observed in the ISD spectra of peptides containing an $\mathrm{N}$-terminal Pro residue, i.e., ACTH19-36 and $\left[\mathrm{Arg}^{36}\right]$-ACTH19-36 (data not shown). Furthermore, the peptide containing both $\mathrm{N}$ - and Cterminal Pro residues, ACTH19-36, showed fragments corresponding to $[\mathrm{M}+\mathrm{H}-28]^{+}$and $[\mathrm{M}+\mathrm{H}-44]^{+}$ (data not shown). The fragment $[\mathrm{M}+\mathrm{H}-28]^{+}$may have originated from the loss of $\mathrm{CO}$ from the $\mathrm{C}$-terminal carboxyl group bound to the Pro residue. The formation of these fragment ions described above is illustrated in Schemes $\mathbf{2}$ and $\mathbf{3}$.

The ISD spectra of peptides obtained with 2,5-DHB and 5-ASA showed $[c-45]^{+},[c-43]^{+}$, and $[c-15]^{+}$, as shown in the MALDI-ISD spectrum of $\left[\mathrm{pTyr}^{6}\right.$, pSer ${ }^{14}$-ACTH18-35 (Figure 5a and b), while the ISD spectra with 1,5-DAN did not show such fragment ions (Figure 1a). The ion of $[c-15]^{+}$might be assigned as the loss of $\mathrm{NH}$ from the N-terminal amino group, as described above. On the other hand, the ions of [c $45]^{+}$and $[c-43]^{+}$are likely to correspond to $a$ - and $(a+2)$-series ions, respectively. The peak abundance of $a$ - and $(a+2)$-series ions seems to be dependent upon the amino acid residues. The peak abundance of $a$ - and $(a+2)$-series ions for several amino acid residues of the peptide $\left[\mathrm{pTyr}^{6}, \mathrm{pSer}^{14}\right]$-ACTH18-35 are shown in Figure $5 c$. In the spectra in Figure $5 c$, the $(a+2)$-series ions were observed independent of amino acid residues. However, the abundance of the $a$-series ion relative to that of the corresponding $(a+2)$-series ion seems to be dependent on the amino acid residues. The $a 9$ ion was not observed in the $\mathrm{C} \alpha-\mathrm{C}$ bond cleavage at the Gly9 residue (G9 of Figure 5c). The lack of $a$-series ion at the Gly residue can be seen in the MALDI-ISD spectra reported previously $[13,16,23]$. A structural characteristic of Gly residues compared to other amino-acids is the lack of a $\beta$-carbon $\left(C_{\beta}\right)$. From this, two possible fragmentation pathways (I and II) with hydrogen transfer from the $\beta$-carbon to form the $a$-series ions can be proposed as shown in Scheme 4 . To ascertain the most probable pathway for the formation of the $a$-series ions, a $C_{\beta}$ deuterium labeled dodecapeptide with $\operatorname{Ala}\left(\mathrm{d}_{3}\right)$ was used in MALDI-ISD experiments [13]. The MALDIISD spectrum of the deuterium labeled peptide showed fragment ions at $\mathrm{m} / \mathrm{z} 802$ and 847 corresponding to $a 7$ and $c 7$ ions, respectively (data not shown). The resulting mass difference of $45 \mathrm{Da}$, between the $a 7$ and $c 7$ ions, suggests that $a$-series ions are caused by pathway II in Scheme 5. The formation of the $(a+2)$-series ions can be explained due to cleavage with hydrogen transfer at the $\mathrm{C} \alpha-\mathrm{C}$ bond (Scheme 5). Furthermore, the abundance of $a$-series ions results from the fact that cleavage at the Glu residue is higher than for other amino acid residues (E11 and D12 of Figure 5c). This fragmentation characteristic is useful in practical terms

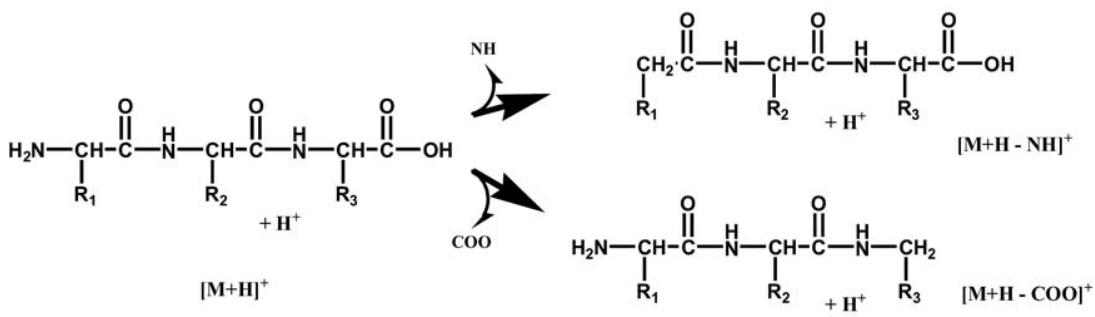

Scheme 2 


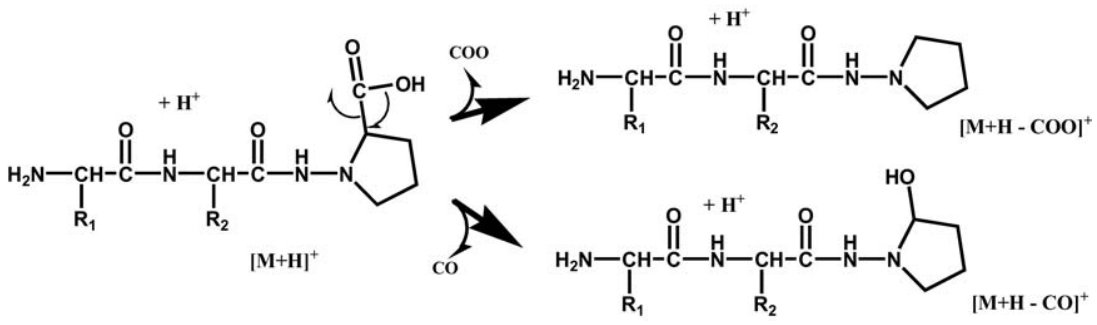

Scheme 3

for confirming the presence and site of Glu residues in analyte peptides. The loss of $45 \mathrm{Da}$ from $\mathrm{c}$-series ions from the Glu residue may be due to the loss of the carboxyl group from the side chain of the Glu residue. It has been reported that the fragment ions originated from the $\mathrm{C} \alpha-\mathrm{C}$ bond cleavage, type III ions named by Soltwisch et al., decrease in abundance with increasing collisional cooling gas pressure and increase with increasing laser fluence [20]. This suggests that the formation of type III ions strongly depends on internal

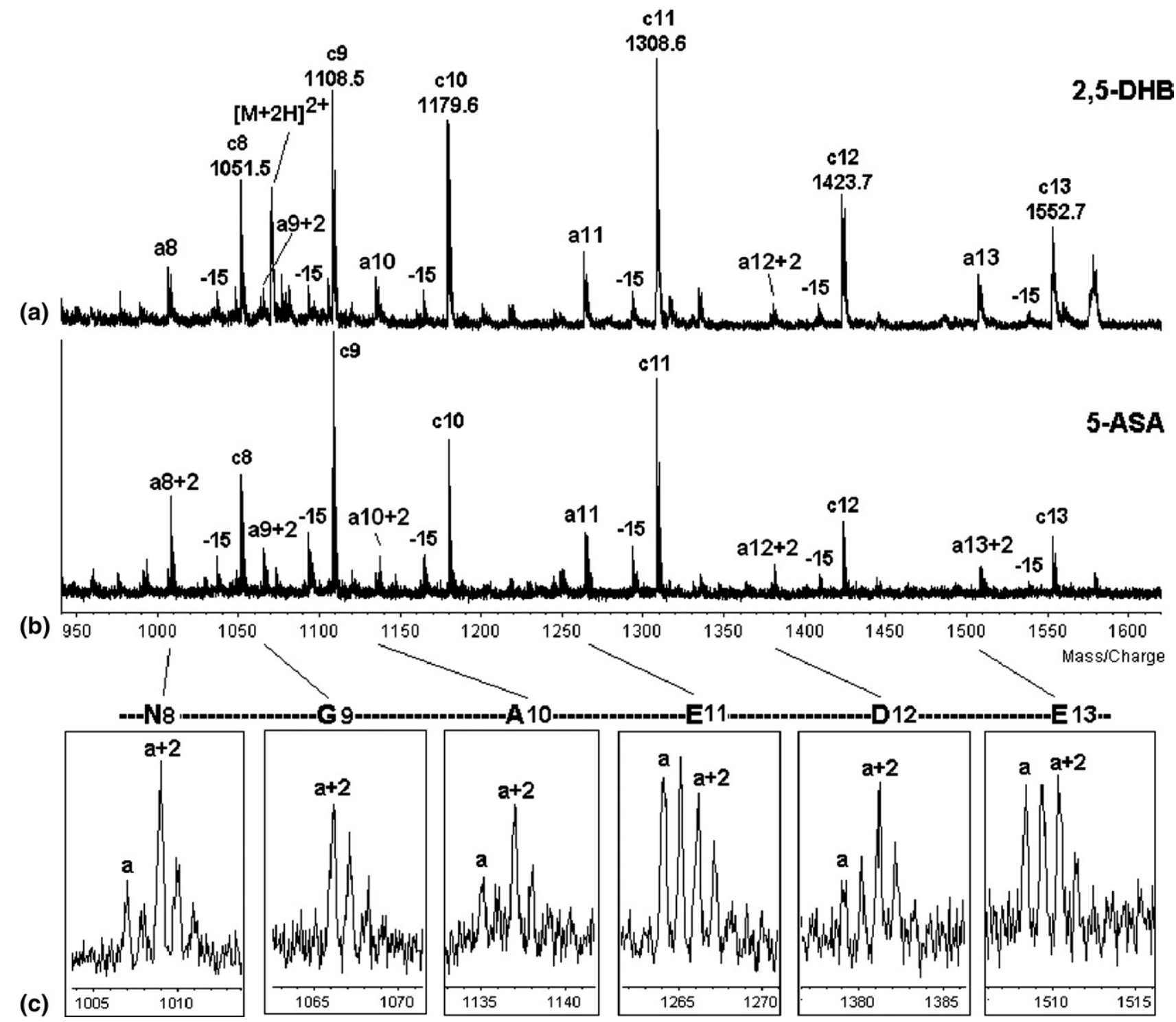

Figure 5. Partial MALDI-ISD spectra of di-phosphorylated peptide $\left[\mathrm{pTyr}{ }^{6}, \mathrm{pSer}^{14}\right]-\mathrm{ACTH} 18-35$ (Mr 2139.1) obtained with (a) 2,5-DHB and (b) 5-ASA. (c) The abundance of $a$ - and $(a+2)$-series ions observed in the MALDI-ISD spectrum with 5-ASA. The $a$ - and $(a+2)$-series ions formed by cleavage at the $\mathrm{C} \alpha-\mathrm{C}$ bond at the C-terminal side of N8, G9, A10, E11, D12, and E11 residues. 

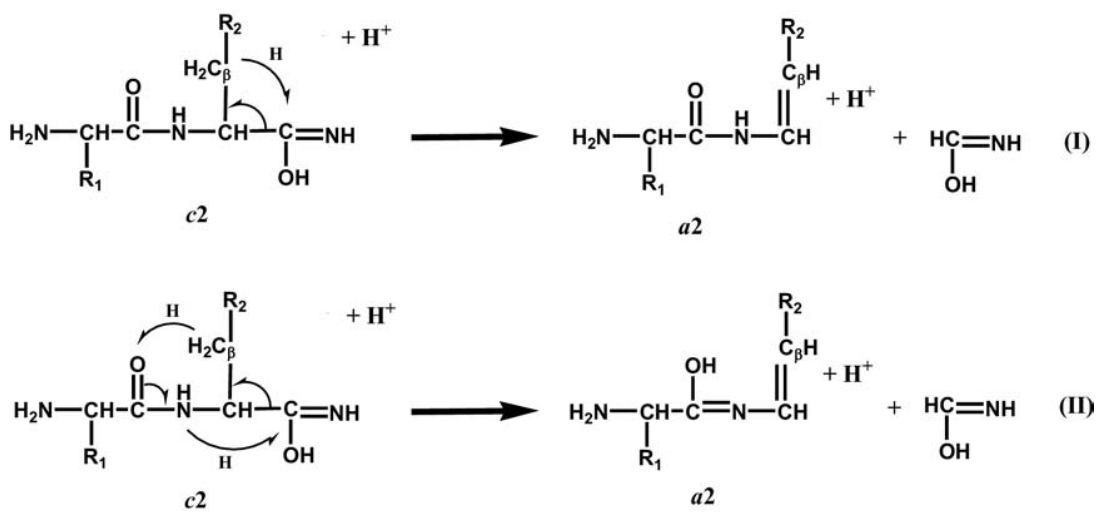

Scheme 4

energy contents of peptide ions produced under MALDI conditions, although Soltwisch et al. have described that type III ions may be produced by a combination of $b$-type and $c$-type ion formation [20]. The mechanism(s) and relationships of the cleavages at $\mathrm{C} \alpha-\mathrm{C}, \mathrm{C}-\mathrm{N}$, and $\mathrm{N}-\mathrm{C} \alpha$ bonds on the peptide backbone in MALDI-ISD will be reported in the future.

\section{5-ASA in MALDI-ISD}

We investigated the ISD properties of the matrices 5-ASA, 2,5-DHB, 1,5-DAN, SA, and CHCA. The properties were measured by using the ratio of the peak abundance of the reduced ion $[\mathrm{M}+2 \mathrm{H}+\mathrm{H}]^{+}$to that of the non-reduced ion $[\mathrm{M}+\mathrm{H}]^{+}$of the peptide $\left[\mathrm{Arg}^{8}\right]-$ vasopressin, which contains a disulfide bond (S-S) between Cys1 and Cys6. The inset in Figure 6 shows the MALDI mass spectrum of $\left[\mathrm{Arg}^{8}\right]$-vasopressin obtained with 5-ASA. The spectrum shows an abundant peak corresponding to the reduced ion $[\mathrm{M}+2 \mathrm{H}+\mathrm{H}]^{+}$at $m / z$ 1086.6. Interestingly, the spectrum does not show any fragment ions originating from ISD, while it was reported that the MALDI mass spectrum of $\left[\mathrm{Arg}^{8}\right]$-vasopressin reduced with dithiothreitol showed mainly $y$ - and $(z+$ $2)$-series ions [25]. This suggests that the ISD process involving hydrogen transfer occurs as a single event in the ion source, i.e., a reductive reaction at the $\mathrm{S}-\mathrm{S}$ bond or cleavage reaction at the $\mathrm{N}-\mathrm{C} \alpha$ bond. The single event characteristic in MALDI-ISD is advantageous for specific cleavage on the peptide backbone, and the subsequent sequence analysis is very easy to perform.

The hydrogen-donating ability estimated from the ratio of peak abundance of reduced ion $[\mathrm{M}+2 \mathrm{H}+$
$\mathrm{H}]^{+}$to that of non-reduced ion $[\mathrm{M}+\mathrm{H}]^{+}$of $\left[\mathrm{Arg}^{8}\right]-$ vasopressin is shown in Figure 6. CHCA was used as a control because CHCA does not show any reductive or ISD reactions. Although Katta et al. have successfully obtained continuous $c$-series ions in the MALDI-ISD of proteins such as r-metHuLeptin (Mr 16,155.6) and r-metHuGDNF (Mr 30,386) by using SA matrix [26], the use of SA in the MALDI-ISD of [ $\left.\mathrm{Arg}^{8}\right]$-vasopressin did not result in products such as $c$-series ions and reductive ions. The order of the ascertained hydrogendonating ability was 1,5-DAN $>5$-ASA $>2,5-\mathrm{DHB}>\mathrm{SA}=$ $\mathrm{CHCA} \sim 0$. Although the result indicates that 1,5-DAN is the most suitable for MALDI-ISD, it should be noted that 1,5-DAN causes contamination of the MALDI ion source due to its sublimation properties. Furthermore, $1,5-\mathrm{DAN}$ is a suspected carcinogen as are other aminonaphthalenes [18]. In contrast, 5-ASA, novel at least in MALDI terms, has been used in the therapy of inflammatory disease for over $50 \mathrm{y}$ [27]. Thus, 5-ASA is more highly recommended as a matrix suitable for MALDIISD of peptides than 1,5-DAN.

\section{Conclusions}

MALDI-ISD has been recognized as a strategic method for peptide and protein identification in proteomics [15, $18,28]$. The most significant feature of MALDI-ISD is the specific cleavage of the $\mathrm{N}-\mathrm{C} \alpha$ bond of the peptide backbone without degradation or loss of side chains and PTM functional groups. Furthermore, a remarkable feature of MALDI-ISD is the use of hydrogen atoms to form peptide/protein radicals that enable ready and rapid cleavage of the $\mathrm{N}-\mathrm{C} \alpha$ bond. To improve MALDI-

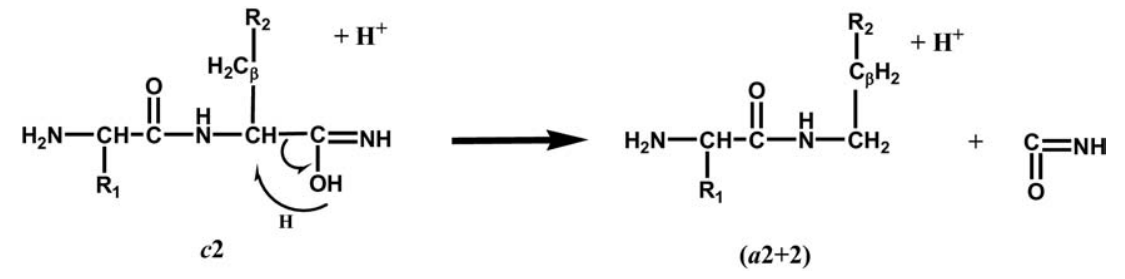

Scheme 5 


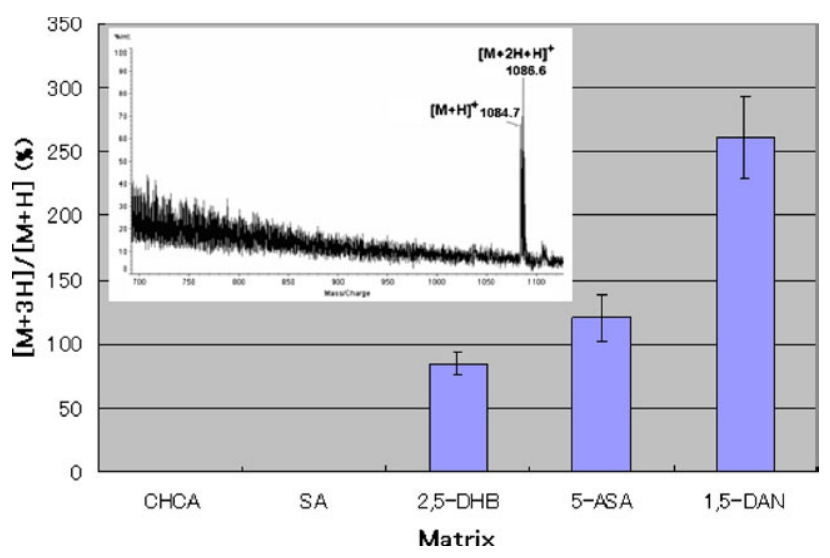

Figure 6. Diagram of reductive ability onto $\left[\mathrm{Arg}^{8}\right]$-vasopressin (Mr 1084.2) containing a disulfide bond, S-S, for several MALDI matrices. The inset indicates the MALDI mass spectrum of the vasopressin obtained with 5-ASA.

ISD, therefore, finding a suitable MALDI matrix that has high hydrogen-donating ability and effective hydrogen transfer to the backbone carbonyl oxygen is an important issue. Furthermore, it is also preferable to look for less toxic chemicals.

The chemical 5-ASA as a matrix introduced here for MALDI-ISD of peptides demonstrates several notable properties compared with conventional matrices such as 2,5-DHB and 1,5-DAN: (1) fewer interference peaks such as those from multiply protonated molecules and metastable peaks, (2) sharpness in the separation of isotope peaks of molecular and ISD fragment ions, and (3) less toxicity. In particular, the application of 5-ASA to mono- and di-phosphorylated peptides gave ISD spectra showing $c$-series ions without any degradation or loss of phosphoric groups and without peak broadening over a wide range of $\mathrm{m} / \mathrm{z}$ including molecular ions. Furthermore, the MALDI-ISD spectra obtained with 5-ASA showed informative fragment ions for sequence analysis, such as $[\mathrm{M}+\mathrm{H}-\mathrm{NH}]^{+},[\mathrm{M}+\mathrm{H}-$ $\mathrm{CO}]^{+},[\mathrm{M}+\mathrm{H}-\mathrm{COO}]^{+},[c-45]^{+}$, and $[c-43]^{+}$. The fragments $[\mathrm{M}+\mathrm{H}-\mathrm{NH}]^{+}$and $[\mathrm{M}+\mathrm{H}-\mathrm{CO}]^{+}$were useful for confirming the presence or absence of a Pro residue at the $\mathrm{N}$ - and C-terminus, respectively. The fragment ion $[c-45]^{+}$corresponding to $a$-series ion originating from cleavage at the $C \alpha-C$ bond was not observed at Gly as this residue lacks a $\beta$-carbon, instead only the fragment $[c-43]^{+}$was observed. In contrast, the peak abundance of the fragment ion $[c-45]^{+}$was higher than that of $[c-45]^{+}$in the $\mathrm{C} \alpha-\mathrm{C}$ bond cleavage at the Glu residue. Consequently, the fragment ions [ $c-$ $45]^{+}$and $[c-43]^{+}$were useful for confirming the presence or absence of Gly and Glu residues in the analyte peptides. The use of 5-ASA in the MALDI-ISD of peptides including mono- and di-phosphorylated peptides produced useful fragment ions without peak broadening or any interference peaks such as metastable peaks and multiply protonated molecules. Furthermore, 5-ASA showed medium levels of reductive activ- ity producing cleavage of the S-S bond. Finally, the chemical 5-ASA can be classified as a "reductive cool" matrix suitable for the MALDI-ISD of peptides.

\section{Acknowledgments}

The authors acknowledge support for this work by the Creation of Innovation Centers for Advanced Interdisciplinary Research Area in the Special Coordination Fund for Promoting Science and Technology, and partial support by Grant-in-Aid for Scientific Research (18550078) from the Japan Ministry of Education, Culture, Sports, and Technology. The authors thank Koichi Tanaka of Shimadzu Corporation for his informative suggestions on the matrix properties.

\section{References}

1. Karas, M.; Bachmann, D.; Bahr, U.; Hillenkamp, F. Matrix-Assisted Ultraviolet Laser Desorption of Non-Volatile Compounds. Int. J. Mass Spectrom. Ion Processes 1987, 78, 53-68.

2. Tanaka, K.; Waki, H.; Ido, Y.; Akita, S.; Yoshida, T. Protein and Polymer Analyses up to $m / z 100,000$ by Laser Ionization Time-of-Flight Mass Spectrometry. Rapid Commun. Mass Spectrom. 1988, 2, 151-153.

3. Karas, M.; Hillenkamp, F. Laser Desorption Ionization of Proteins with Molecular Masses Exceeding 10,000 Daltons. Anal. Chem. 1988, 60, 2299-2301.

4. Whitehouse, C. M.; Dreyer, R. N.; Yamashita, M.; Fenn, J. B. Electrospray Interface for Liquid Chromatographs and Mass Spectrometers. Anal. Chem. 1985, 57, 675-679.

5. Fenn, J. B.; Mann, M.; Meng, C. K.; Wong, S. F.; Whitehouse, C. M. Electrospray Ionization for Mass Spectrometry of Large Biomolecules. Science 1989, 246, 64-71.

6. Derrick, P.; Patterson, S. Mass Spectrometry of Proteomics. Proteomics 2001, 1, 919-1058.

7. Abu-Farha, M.; Elisma, F.; Zhou, H.; Tian, R.; Zhou, H.; Asmer, M. S.; Figeys, D. Proteomics: From Technology Developments to Biological Applications. Anal. Chem. 2009, 81, 4585-4599.

8. Zubarev, R. A.; Kelleher, N. L.; McLafferty, F. W. Electron Capture Dissociation of Multiply Charged Protein Cations. A Nonergodic Process. J. Am. Chem. Soc. 1998, 120, 3265-3266.

9. Syka, J. E.; Coon, J. J.; Schroeder, M. L.; Shabanowitz, J.; Hunt, D. F. Peptide and Protein Sequence Analysis by Electron Transfer Dissociation Mass Spectrometry. Proc. Natl. Acad. Sci. U.S.A. 2004, 101, $9528-$ 9533.

10. Brown, R. S.; Lennon, J. Sequence-Specific Fragmentation of MatrixAssisted Laser-Desorbed Protein/Peptide Ions. J. Anal. Chem. 1995, 67, 3990-3999.

11. Coon, J. J. Collisions or Electrons? Protein Sequence Analysis in the 21st Century. Anal. Chem. 2009, 81, 3208-3215.

12. Biemann, K. Contributions of Mass Spectrometry to Peptide and Protein Structure. Biomed. Environ. Mass Spectrom. 1988, 16, 99-111.

13. Takayama, M. N-C Bond Cleavage of the Peptide Backbone Via Hydrogen Abstraction. J. Am. Soc. Mass Spectrom. 2001, 12, 1044-1049.

14. Koecher, T.; Engstroem, A.; Zubarev, R. A. Fragmentation of Peptides in MALDI In-Source Decay Mediated by Hydrogen Radicals. Anal. Chem. 2005, 77, 172-177.

15. Hardouin, J. Protein Sequence Information by Matrix-Assisted Laser Desorption/Ionization In-Source Decay Mass Spectrometry. Mass Spectrom. Rev. 2007, 26, 672-682.

16. Takayama, M. In-source Decay Characteristics of Peptides in MatrixAssisted Laser Desorption/Ionization Time-of-Flight Mass Spectrometry. I. Am. Soc. Mass Spectrom. 2001, 12, 420-427.

17. Fukuyama, Y.; Iwamoto, S.; Tanaka, K. Rapid Sequencing and Disulfide Mapping of Peptides Containing Disulfide Bonds by Using 1,5-Diaminonaphthalene as a Reductive Matrix. J. Mass Spectrom. 2006, 41, 191-201.

18. Demeure, K.; Quinton, L.; Gabelica, V.; De Pauw, E. Rational Selection of the Optimum MALDI Matrix for Top-Down Proteomics by In-Source Decay. Anal. Chem. 2007, 79, 8678-8685.

19. See the pollution information site, http://www.scorecard.org/cehmicalprofiles/.

20. Soltwisch, J.; Souady, J.; Berkenkamp, S.; Dreisewerd, K. Effect of Gas Pressure and Gas Type on the Fragmentation of Peptide and Oligosaccharide Ions Generated in an Elevated Pressure UV/IR-MALDI Ion Source Coupled to an Orthogonal Time-of-Flight Mass Spectrometer. Anal. Chem. 2009, 81, 2921-2934.

21. Dreisewerd, K. The Desorption Process in MALDI. Chem. Rev. 2003, 103, 395-425.

22. O'Connor, P. B.; Hillenkamp, F. MALDI MS-A Practical Guide to Instrumentation, Methods, and Applications; Wiley-VCH Verlag $\mathrm{GmbH}$ and KGaA: Weinheim, 2007; p. 35-38. 
23. Takayama, M.; Tsugita, A. Does In-Source Decay Occur Independent of the Ionization Process in Matrix-Assisted Laser Desorption? Int. J. Mass Spectrom. Ion Processes 1998, 181, L1-L6.

24. Kinumi, T.; Niwa, H.; Matsumoto, H. Phosphopeptide Sequencing by In-Source Decay Spectrum in Delayed Extraction Matrix-Assisted Laser Desorption Ionization Time-of-Flight Mass Spectrometry. Anal. Biochem. 2000, 277, 177-186.

25. Takayama, M.; Tsugita, A. Sequence Information of Peptides and Proteins with In-Source Decay in Matrix Assisted Laser Desorption/ Ionization-Time of Flight-Mass Spectrometry. Electrophoresis 2000, 21, $1670-1677$.
26. Katta, V.; Chow, D. T.; Rohde, M. F. Applications of In-Source Fragmentation of Protein Ions for Direct Sequence Analysis by Delayed Extraction MALDI-TOF Mass Spectrometry. Anal. Chem. 1998, 70, 4410-4416

27. Salazopyrin, S. N. A New Sulfanilamide Preparation: A. Therapeutic Results in Rheumatic Polyarthritis. B. Therapeutic Results in Ulcerative Colitis. C. Toxic Manifestations in Treatment with Sulfanilamide Preparation (2nd ed.). Acta Med. Scand. 1942, 110, 557-590.

28. Detlev, C. Y.; Sauerland, V.; Ronk, M.; Ma, M. Toward Top-Down Determination of PEGylation Site Using MALDI In-Source Decay MS Analysis. J. Am. Soc. Mass Spectrom. 2009, 20, 326-333. 